\title{
Landsat TM Image Based Dynamic Analysis of Desertification Landscape Pattern in Xilin Gol League
}

\author{
Yanqi Wang ${ }^{1}$, Yin Shan ${ }^{1}$, Enliang Guo ${ }^{1,2}$, Xiuqing Peng ${ }^{1}$, Yuwei Li ${ }^{1}$, Lili Hou ${ }^{1}$, Ru \\ $\mathrm{Ya}^{1}$, Lumen $\mathrm{Chao}^{3}$ \\ ${ }^{1}$ College of Geographical Sciences, Inner Mongol Normal University, Hohhot 010022, China \\ ${ }^{2}$ Inner Mongolian Key Laboratory of Remote Sensing \& Geography Information System, \\ Inner Mongol Normal University, Hohhot 010022, China \\ ${ }^{3}$ Inner Mongolia Autonomous Region Center for Ecology and Agrometeorology, Hohhot \\ 010051, China
}

\section{基于 landsat TM 影像的锡林郭勒盟沙漠化景观 格局动态分析}

\author{
王艳琦 ${ }^{1}$, 银山 ${ }^{1}$, 郭恩亮 ${ }^{1,2}$, 彭秀清 ${ }^{1}$, 李雨薇 ${ }^{1}$, 侯丽丽 ${ }^{1}$, 雅茹 ${ }^{1}$, 朝鲁门 ${ }^{3 *}$ \\ '蒙古师范大学, 地理科学学院, 呼和浩特 010022 , 中国 \\ ${ }^{2}$ 内蒙古师范大学, 内蒙古自治区遥感与地理信息重点实验室, 呼和浩特 010022 , 中国 \\ ${ }^{3}$ 内蒙古自治区生态与农业气象中心, 呼和浩特 010051 , 中国
}

\begin{abstract}
This paper uses the Xilin Gol League as a research area, based on Landsat $\mathrm{TM}$ and meteorological data for the past 15 years, selects three periods of remote sensing images to use RS, GIS technology and dynamic degree and landscape index to select the landscape pattern and desertification dynamics of sandy land from 2000 to 2015. The driving force factor is analyzed. The results show that the degree of fragmentation of the sandy landscape in the Xilin Gol district was reduced from 2000 to 2015 , the landscape patch area was regularized, and the disturbance intensity of human activities on sandy land was reduced; the degree of desertification generally showed a reversal trend, but there was a development
\end{abstract}

trend during the period. Further research shows that from 2000 to 2015, the main factors affecting the reversal of desertification are the increase of precipitation and the implementation of national and local policies in order to provide a theoretical basis for the desertification control project of the motherland and the protection of ecological security in the Beijing-Tianjin-Hebei region.

Keywords: Landscape pattern of sandy land; dynamics of desertification; driving forces

摘要

本文以锡林郭勒盟为研究区, 基于 Landsat TM 和近 15 年气象数据, 选取三期 遥感影像利用 RS、GIS 技术和动态度以及通 过景观指数的选取对 2000-2015 年沙地景观 格局和沙漠化动态变化及其驱动力因素进 
行分析。结果表明: 2000-2015 年锡林郭勒 地区沙地景观的破碎化程度减少, 景观斑块 趋于规则化, 人类活动对于沙地的干扰强度 降低; 沙漠化程度总体呈现逆转趋势, 但期 间存在发展趋势。进一步研究表明, 2000-2015 年, 影响沙漠化逆转的主要因素 为降水量的增加和国家与地方政策的实施, 以期为祖国边疆沙漠化治理工程以及保护 京津冀地区生态安全提供理论依据。

关键词: 沙地景观格局; 沙漠化动态; 驱动 力因素

\section{1. 引言}

受全球气候变化和人类活动干扰而引 发的生态灾害已对人类的公共安全和社会 可持续发展构成威胁, 其中沙漠化是最为严 重的生态灾害之一 [1]。沙漠化问题是干旱、 半干旱及部分半湿润地区由于人地关系不 相协调所造成的以风沙活动为主要标志的 土地退化 $[2-3]$ 。锡林郭勒盟为内蒙古典型 草原区, 位于东亚季风边缘, 受气候变化与 人类活动影响沙漠化灾害较为严重 [4]。

近些年, 遥感手段在沙漠化监测研究中 得到广泛应用 [5-9], 一些学者 [10-14]运用 GIS 或 RS 技术对内蒙古地区科尔沁沙地、 毛乌素沙地和浑善达克沙地等不同地区的 沙漠化过程、景观结构及成因等方面进行了 研究。在全球变暖背景之下沙漠化问题日趋 显著, 一些学者 [15-18] 从气候变化和人类 活动的角度来分析沙漠化发展或逆转的驱 动因素。

本文基于遥感和气象数据, 对锡林郭勒 盟整个地区 2000 年、 2010 年和 2015 年三个 时期内土地利用类型进行目视解译, 沙地信 息进行提取, 分析该地区沙地景观格局变化 特征和沙漠化动态及其驱动因素, 对于促进 祖国北部边疆生态屏障的建设有着重要的 理论及现实意义。

\section{2. 数据和方法}

\section{1 研究区域介绍}

锡林郭勒盟 ( $111^{\circ} 59^{\prime}-120^{\circ} 01^{\prime} \mathrm{E}$, $42^{\circ} 32^{\prime}-46^{\circ} 51^{\prime} N$ ）隶属内蒙古自治区, 位 于我国中温带干早、半干早地区, 属东部草
原和西部干旱区的过渡带, 是典型的农牧交 错地区, 土地面积 $2.03 \times 10^{5} \mathrm{~km}^{2}$ (图 1), 冬 季寒冷夏季炎热, 冬春季风沙天气较多, 降 水量集中在夏季且分布不均, 年均降水量在 200-350mm 间, 年均蒸发量 1700-2600mm 之 间 [19]。

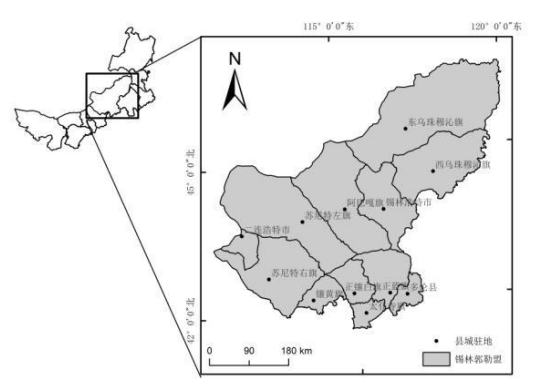

图 1.研究区区位图

\section{2 指标权重确定方法的选择数据来源与}

\section{处理}

\subsection{1 影像处理及信息提取}

遥感数据为 2000 年、 2010 年和 2015 年 7、8 月份三期 Landsat TM 产品数据, 空间 分辨率为 $30 \mathrm{~m} \times 30 \mathrm{~m}$, 数据在美国宇航局 $\mathrm{NSGS}$ 网站 (http//www. nsgs. com) 直接下载。应 用 ENVI5. 1 进行标准假彩色波段合成, 再利 用 Arcgis10.3 软件对影像进行目视解译提 取土地利用信息, 统计相关数据。气象数据 从中国气象科学共享服务网 (http: //cdc. cma. gov. cn/) 下载, 获取了锡林郭勒 盟 2000-2015 年季起风沙天数, 月降水量、 月平均气温。社会经济数据数据来自内蒙古 自治区统计年鉴。

\subsection{2 动态度}

动态度表征各个景观的变化幅度和速 度, 用转移矩阵分析各土地覆盖之间的相互 转移, 以此来揭示研究区景观变化的规律及 特点 [20]。沙漠化动态度是反映单位时间内 沙漠化土地变化程度即年增长率的指标 [21-22]。其计算公式如下:

$$
S D=\frac{A_{j}-A_{i}}{A_{i}} \times \frac{1}{T} \times 100 \%
$$

式中: $S D$ 为某地或某类型沙漠化土地的动 
态变化; $A \mathrm{i}$ 为起始年沙漠化土地面积; $A_{j}$ 为终结年沙漠化土地面积; $T$ 为间隔年限。 正值表示该研究区沙漠化土地面积在增加, 负值表示该研究区沙漠化土地面积在减少。

\section{2 .3 景观格局指数}

景观指数是指能够高度浓缩景观格局 信息, 反映其结构组成和空间配置某些方面 特征的简单定量指标 [23]。本文基于目视解 译栅格数据结果, 采用 Fragstats4. 2 在景观 水平选取 6 个指标, 包括: 斑块面积 (CA)、 斑块数 (NP)、斑块密度 (PD)、最大斑块 指数 (LPI:)、景观形状指数 (LSI)、聚集 度 ( $\mathrm{AI}$ ), 对锡林郭勒盟地区沙漠化土地的 景观格局特征及变化进行了分析。

\section{3. 结果分析}

\section{1 基于组合权重的评价公式确定}

如表 1, 2000 年、2010 年和 2015 年斑 块面积分别为 $478202.1 \mathrm{~km}^{2} 、 362866.5 \mathrm{~km}^{2}$ 、 $365478.8 \mathrm{~km}^{2}$, 总体呈现减少趋势; 斑块个

表 1 . 景观格局指数动态统计表

\begin{tabular}{ccccccc}
\hline 年份 & CA & NP & PD & LPI & LSI & AI \\
\hline 2000 & 478202.1 & 3462 & 0.0173 & 0.0618 & 110.2984 & 95.2554 \\
2010 & 362866.5 & 3266 & 0.0163 & 0.0546 & 101.4619 & 94.9942 \\
2015 & 365478.8 & 3285 & 0.0164 & 0.0547 & 101.7172 & 94.9987 \\
\hline
\end{tabular}

注: CA: 斑块面积 (单位: $\mathrm{km}^{2}$ ); $\mathrm{NP}$ : 斑块数 (单位: 个); PD: 斑块密度 (单位: 个 $/ \mathrm{km}^{2}$ ); $\mathrm{LPI}$ 最大 斑块指数; LSI: 景观形状指数; AI: 聚集度指数（单位：\%)

\section{2 沙漠化动态变化}

2000 年, 研究区沙地总面积为 $4782.15 \mathrm{~km}^{2}$ (表 2); 2010 年为 $3628.48 \mathrm{~km}^{2}$; 2015 年为 $3654.59 \mathrm{~km}^{2}$ 。2000-2015 年, 沙漠 化动态度是 -0.15 , 说明沙地面积呈现减少 趋势; 2000-2010 年, 沙漠化动态度是-0. 24, 说明沙地面积呈现减少趋势; 2010-2015 年, 沙漠化动态度是 0.01 , 说明沙地面积呈现增 加趋势。近十五年来, 锡林郭勒盟地区沙漠 化呈逆转趋势, 但 2010 年之后沙漠化又有 所发展。

\section{2 驱动力分析}

\subsection{1 气候特征}

区域气候变化是沙漠化程度变化的主 要自然动力因素, 降水量、气温以及起沙风
数是用来描述景观的异质性, 2000-2015 年, 总体斑块个数和斑块密度均呈现减少趋势, 2000-2015 年斑块个数由 3462 个减少到 3285 个, 说明锡盟沙地景观的破碎化程度减 少; 斑块密度由 0.0173 个 $/ \mathrm{km}^{2}$ 减少到 0.0164 个 $/ \mathrm{km}^{2}$, 说明沙地承载力抗自然灾害能力 增强。期间就斑块个数和斑块密度而言, 2000-2010 年呈大幅度减少趋势, 而 2010-2015 年呈现略微增加趋势, 说明 2000-2015 年, 沙漠化景观的破碎化程度呈 现先减少后增加趋势。2000-2015 年, 景观 形状指数呈先下降后上升趋势, 总体呈下降 趋势, 表明 2000-2015 年沙漠化景观斑块趋 于规则化, 不容易受到周围景观的影响。聚 集度指数在 2000 年、2010 年、2015 年分别 为 $95.2554 \% 、 94.9942 \% 、 94.9987 \%$, 趋于减 小趋势, 说明沙地聚集程度减少。2000-2015 年, 最大斑块指数由 0.0618 减少到 0.0547 , 说明人类活动对沙地的干扰强度降低。 
大幅度减少趋势, 说明影响沙漠化变化的主 要气候因素为降水量。2000-2010 年, 沙地 面积减少, 沙漠化程度减轻, 这个时期该地 区年平均气温因素稳定, 而年平均降水量由 $203 \mathrm{~mm}$ 增加到 $243 \mathrm{~mm}$, 降水量的增多, 加大 了植被覆盖度, 说明该时期降水是该地区沙 漠化变化主要气候因素; 2010-2015 年, 沙 地面积略微增加, 年平均降水量由 $243 \mathrm{~mm}$ 增 加到 $246 \mathrm{~mm}$, 年平均降水量略有增加使得湖 泊和沼泽地面积有所扩大, 而年平均气温呈 持续下降趋势且均低于近 15 年平均气温, 气温的降低影响植被的物候, 使得植被返青 期延后, $7 、 8$ 月植被生长不好, 使得草地退 化现象明显, 是导致沙漠化程度开始恶化重 要气候因素。

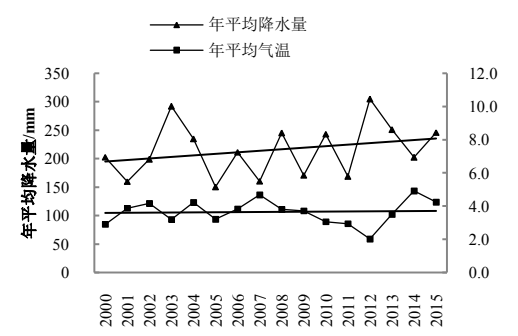

年份

图 2 2000-2015 年锡林郭勒盟年平均降水 量与气温统计图

锡林郭勒盟地区受西北季风影响大, 大 风日数较多, 年平均起沙风速 $\geqslant 4.5 \mathrm{~m} / \mathrm{s}$ 天数 约为 90 天, 风速的增大能够加快地表物质 的风化程度, 加大该地区的沙漠化程度。 2000-2015 年, 年平均起沙风速 $\geqslant 4.5 \mathrm{~m} / \mathrm{s}$ 天 数在 60-110 天之间波动变化, 2000-2010 年, 年平均起沙风速 $\geqslant 4.5 \mathrm{~m} / \mathrm{s}$ 天数呈现波动上 升趋势, 直到 2010 年, 达到近 15 年的波峰 值为 110 天, 风沙天数的增加是 2010 年沙 漠化程度加剧的重要因素之一。2010 年之后, 年平均起沙风速 $\geqslant 4.5 \mathrm{~m} / \mathrm{s}$ 天数开始减少, 直 到 2015 年减少到最低值, 起风沙天数的减 少是沙漠化程度逆转的因素之一。

\subsection{2 社会经济因素与沙漠化动态}

人为因素作为沙漠化动态变化的可控 因素, 人口数量大幅增加会导致资源的过度 开发与利用, 造成了各种经济压力 [25]。

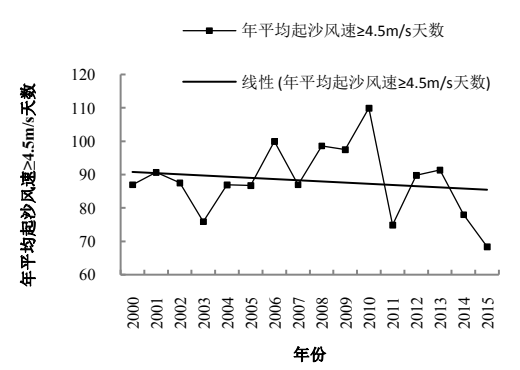

图 3 2000-2015 年锡林郭勒盟年平均起沙风 天数 $(\geqslant 4.5 \mathrm{~m} / \mathrm{s})$ 统计图

图 4 表明, 2000-2015 年, 人口总体呈 现增长趋势, 由 91 万人增加到 104 万人; 大牲畜数量呈现增加趋势, 由 97.41 万头增 加到 103.37 万头。该地区人口容量和环境 承载力有限的前提下, 人口与大牲畜的持续 上升会加剧该地区生态环境的脆弱性。除此 之外, 据调查 2000 年国家开始实施退耕还 林还草和京津风沙源治理工程 [26], 其重点 是对内蒙古自治区的风沙治理。2000 年以来, 该地区沙漠化逆转明显, 说明国家与地方政 策的实施是沙漠化变化的主导社会经济因 素。

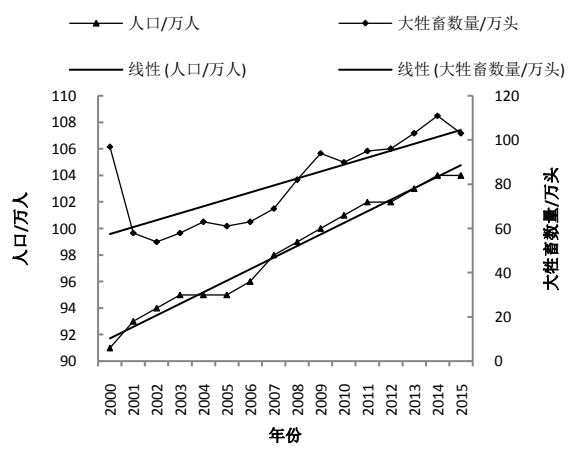

图 4 2000-2015 年锡林郭勒盟人口与大牲畜 数量变化统计图

\section{4. 结论}

本文选取锡林郭勒盟地区为研究区, 对 该研究区沙地景观格局特征与沙漠化程度 进行分析, 并从自然与社会经济因素就沙漠 化变化进行定性分析, 结论如下:

2000-2015 年, 锡林郭勒盟地区沙地景 观的破碎化程度减少, 景观斑块趋于规则化, 
人类活动对于沙地的干扰强度降低, 地承载 力抗自然灾害能力增强不容易受到周围景 观的影响; 沙漠化程度总体呈现逆转趋势, 但 2010 年之后沙漠化程度又有所发展。

沙漠化逆转是众多因素共同作用的结 果, 其中降水量的增加和国家政策的支持是 沙漠化逆转的主要驱动因素, 2010 年, 而极 端气候出现气温骤减、大牲畜数量呈现增加 趋势, 对于沙漠化发展有一定的影响。

\section{Acknowledgements}

This research has been supported by the National Natural Science Foundation of China (61631011 and 6155005) and the Ministry of Science and Technology of Inner Mongolia Autonomous Region (2018-ZME-KJXT-14); the project funded by the Graduate Research Fund of Inner Mongolia Normal University -Project of the Postgraduate Education Innovation Program of Inner Mongolia Autonomous Region (S20171013508) Funding.

\section{致谢}

本研究得到了国家自然科学基金重点 项目 (61631011 和 61550005)、内蒙古自治 区科技厅项目（2018-ZME-KJXT-14）、 科技支撑项目 (2017FY101301-4); 内蒙古 师范大学研究生科研创新基金资助项目 (CXJJS17096); 内蒙古自治区研究生教育 创新计划资助项目（S20171013508）资金资 助。

*通讯作者: 朝鲁门 (1981-), 男, 内蒙古 库伦人, 工程师, 主要从事农业气象灾害监 测评估与草地生态环境监测评估工作。 E-mail: 邮箱: chaolumen00@163.com

\section{参考文献}

[1] 朱震达,刘恕.中国北方沙漠化过程与分 区治理.北京:中国林业出版社,1981,3046.

[2] 董玉祥,刘玉璋,刘毅华.沙漠化若干问题 的研究.西安:西安地图出版社,1995,1-25
0.

[3] 王涛,朱震达. 我国沙漠化研究的若干问 题沙漠化的概念及其内涵. 中国沙漠, 20 03,23(3):209-214.

[4] 佟哈斯毕力格. 锡林郭勒草原荒漠化灾 害风险评价. 呼和浩特.内蒙古师范大学, 2013.

[5] 张明. 基于遥感数据的青海湖流域土地 沙漠化评价研究 [J]. 国土与自然资源研 究,2016,0(3):35-37.

[6]段英杰,何政伟,王永前, 刘军峰, 黄纲. 基 于遥感数据的西藏自治区土地沙漠化 监测分析研究.干旱区资源与环境,2014, 28(01):55-61.

[7] 康文平,刘树林,段翰晨. 基于 MODIS 时 间序列数据的沙漠化遥感监测及沙漠 化土地图谱分析——以内蒙古中西部 地区为例.中国沙漠,2016,36(02):307-31 8.

[8] 王莉雯,卫亚星,牛铮.基于 GIS 的沙漠化 土地面积遥感分析监测. 地球信息科 学,2007,9(03):132-134.

[9] 康文平, 刘树林. 沙漠化遥感监测与定量 评价研究综述.中国沙漠, 2014,34(5):

1222-1229.

[10］银山,包玉海,萨日娜. 基于遥感、GIS 的 内蒙古沙漠和沙质荒漠化研究. 干早 区资源与环境,2004,18(9):58- 62.

[11] 常学礼, 于云江, 曹艳英. 半干旱地区沙 地景观破碎化趋势分析. 干旱区研 究,2004,21(1):21-26.

[12] 吴薇. 近 50 年来毛乌素沙地的沙漠化 过程研究.中国沙漠,2001,21(2):164-1 69.

[13] 陈雅琳, 常学礼, 崔步礼, 宋彦华. 库布齐 沙漠典型地区沙漠化动态分析. 中国沙 漠,2008,28(1):27-34.

[14] 美丽,都瓦拉,银山,玉山.基于植被覆盖 特征的土地沙漠化敏感性评价. 干旱区 资源与环境,2017,31(5):113-118.

[15] 董光荣,申建友,金昫,李保生,高尚玉.气 候变化与沙漠化关系的研究.干旱区资 源与环境,1988,2(1):31-45.

[16] 徐小玲, 延军平. 陕北沙区人为因素与 
沙漠化的定量关系研究.干旱区资源与

环境,2005,19(5):38-41.

[17] 王永芳,张继权,马齐云,朱萌.21世纪初 科尔沁沙地沙漠化对区域气候变化 的响应.农业工程学报,2016,32(10):17 7-185.

[18] 李春兰,胡日查,银山,布仁,包玉海,李雨 薇,阿拉腾图雅,包慧娟. 锡林郭勒盟荒 漠化土地动态变化特征研究. 中国灾 害防御协会风险分析专业委员会第七 届年会论文集(2016 年 11 月 4-6 日, 长沙), pp. 793-799.

[19] 张美艳,董建军,辛姝玉,赵达君,张立中. 锡林郭勒盟草原流转牧户的技术效率 研究一基于 DEA-Tobit 模型的分析.干 旱区资源与环境,2017,31(11):62-68.

[20] 温都日娜. 毛乌素沙地荒漠化景观演 变特征研究.中国灾害防御协会风险分 析专业委员会第六届年会论文集(2014 年 8 月 23-27日, 呼和浩特), pp. 574-580
[21] 高晓霞.浑善达克沙地景观格局动态变 化及其驱动力分析.内蒙古大学, 2016 .

[22] JacksonR D, Idso S B, Otterman J. Surface albedo and desertification. Science: New Series, 1975, 189 (4207): 1012- 1015.

[23] 赵健,魏成阶, 黄丽芳, 等.土地利用动态 变化的研究方法及其在海南岛的应用. 地理研究,2001,20(6):723-730.

[24] 段翰晨等,基于 RS 与 GIS 的科尔沁沙 地沙漠化时空演变.中国沙漠,2013,33 (2):470-477.

[25] 李春兰,朝鲁门,包玉海, 银山等. 21 世 纪初期气候波动下浑善达克沙地荒漠 化动态变化分析.干旱区地理,2015,38 (3):556-564.

[26] 银山.内蒙古浑善达克沙地荒漠化动态 研究. 呼和浩特, 内蒙古农业大学博士 学位论文,2010 年. 